\title{
GROWTH INHIBITION OF PLASMODIUM FALCIPARUM AND INTERLEUKIN-8 PRODUCTION BY PERIPHERAL BLOOD MONONUCLEAR AND POLYMORPHONUCLEAR CELLS IN VITRO
}

\author{
JULIETA YURI OHYA ${ }^{1}$, HIROYUKI MATSUOKA ${ }^{1}$, NAOFUMI MUKAIDA ${ }^{2}$, \\ TADASI KASAHARA $^{3}$ and AKIRA ISHII ${ }^{1}$ \\ Accepted November, 19, 2002
}

\begin{abstract}
Peripheral blood mononuclear and polymorphonuclear cells have been demonstrated to kill and inhibit malaria parasite proliferation in vitro, but most of the reports required activation of the cells by cytokines or presence of immune sera or opsonins. In our study, peripheral blood leukocytes from non-immune donor efficiently inhibited Plasmodium falciparum growth, depending on the effecter/target ratio. Moreover, these cells produced a large amount of interlenkin-8 (IL-8) under stimulation with infected erythrocytes or supernatant of the Plasmodium falciparum culture. IL-8 secretion in the culture supernatant of polymorphonuclear cells was noted from 6-9 hr of stimulation with the parasites, with a substantial increase over 24 hours of culture. Attempt to elucidate whether IL8 was involved in malaria suppression was done, and the result suggested that IL- 8 was not directly involved in the anti-malarial activity of the mononuclear and polymorphonuclear cells. The other mechanism besides IL- 8 may work for inhibiting parasite growth in the culture system of malaria parasites associated with leukocytes.

Key words: cytokine, interleukin-8, malaria, mononuclear cell, Plasmodium falciparum, polymorphonuclear cell
\end{abstract}

\section{INTRODUCTION}

Anti-malarial activity of peripheral blood mononuclear cells (MNC) and polymorphonuclear cells (PMN) have been demonstrated (Vernes, 1980; Celada et al., 1983; Nnalue and Friedman 1988; Bouharoun-Tayoun et al., 1990; Kumaratilake et al., 1997), but in most of the reports, presence of opsonising agents (Nnalue and Friedman 1988), antibodies (Celada et al., 1983; Bouharoun-Tayoun et al., 1990) or complements (Kumaratilake et al., 1997) were required. There are considerable evidences showing involvement of cytokines such as tumor necrosis factor $\alpha$ (TNF $\alpha)$, interferon-gamma (IFN $\gamma$ ), interleukin $1 \alpha$ (IL-I $\alpha$ ), and others in the immunity and pathophysiology of malaria (Ockenhouse et al., 1984; Kossodo and Grau, 1993; Kwiatkowski, 1995). The involvement of interleukin-8 (IL-8) and its ligand in Plasmodium vivax infection has been suggested (Horuk, 1994), and this chemokine has been detected in the serum of patients infected with Plasmodium falciparum (P. f.) (Friedland et al., 1993; Looareesuwan et al., 1999), but the roles of IL-8 in falciparum malaria are not clear.

We performed in vitro experiments to study the antimalarial activity of the non-immune peripheral blood leukocytes. Moreover, we studied the IL-8 production of periph- eral blood MNC and PMN induced by P.f., and tried to elucidate the role of this cytokine in immunity to malaria.

\section{MATERIALS AND METHODS}

\section{Malaria parasites}

Plasmodiun falciparum FCR-3 strain has been maintained in our laboratory in a continuous culture according to previous described methods (Trager and Jensen, 1976), except for the serum supplemented to the medium. The parasites were sowed in red blood cells (RBC) at an initial hematocrit of 5\% in RPMI 1640 medium (Sigma Chemical Co, St. Louis, MO, USA) supplemented with $10 \%$ heatinactivated horse serum (Cosmo Bio Co., Tokyo, Japan). Substitution of the human sera with horse sera greatly facilitate the malaria culture, because this permitted the use of all types of human erythrocytes, without checking for compatibility.

\section{Separation of MNC and purification of monocytes}

$50 \mathrm{ml}$ of peripheral venous blood was collected from healthy non-immune donors in a heparinized syringe. MNC were separated by Ficoll/Urografin density gradient centrifugation, and suspended in a plastic dish with RPMI 1640

\footnotetext{
${ }^{1}$ Department of Medical Zoology, Jichi Medical School, Kawachi-gun, Minamikawachi-machi, Tochigi 329-0498, Japan

2 Cancer Research Institute, Kanazawa University, Takara-machi, Kanazawa 920-0934, Japan

${ }^{3}$ Kyoritsu College of Pharmacy, Minato-ku, Tokyo 105-8512, Japan
} 
supplemented with $5 \%$ fetal calf serum. Two hours after incubation at $37{ }^{\circ} \mathrm{C}$, non-adherent cells were removed from the plate by washing with phosphate buffered saline and adherent cells (mainly monocytes) were detached from the plate with a rubber policeman and resuspended in the same medium of MNC.

\section{Separation of PMN}

Once the MNC removed, PMN (about 95\% neutrophils) were separated from RBC by sedimentation in $1.25 \%$ gelatin. Mingled erythrocytes were hemolysed in lysing reagent (Ortho Diagnostic Systems, New Jersey, NJ, USA) and PMN were resuspended in the same medium of MNC.

\section{P.f. growth inhibition assay}

Growth inhibition assay was done by a radiometric method, described by Kumaratilake et al. (1997). Briefly, the experiments were conducted in 96 well flat-bottomed microplates (Becton Dickinson Co., Franklin Lakes, NJ, USA). The cells (MNC or PMN) were subsequently diluted and placed to the wells in $100 \mu \mathrm{l}$ aliquots, where the parasites $\left(1 \times 10^{5}\right.$ parasites in $5 \times 10^{7} \mathrm{RBC}$ in $100 \mu \mathrm{l}$ of medium) were added 2 hours later. Following 48 hours incubation at $37^{\circ} \mathrm{C}$ in a $\mathrm{CO}_{2}$ incubator containing a gas mixture of $5 \%$ $\mathrm{CO}_{2}$ in air, each well was pulsed with $1 \mu \mathrm{Ci}$ of $\left[{ }^{3} \mathrm{H}\right]$ hypoxanthine and harvested 24 hours later on a glass fiber sheet. The disks on the sheet were air dried, placed in a 96 well polyethylene plate with $100 \mu \mathrm{l}$ of toluene scintillant and counted by a microplate scintillation counter (TopCount, Packard Instrument Co., Meriden, CT, USA). Each dilution was made in triplicate and the average was calculated. Growth inhibition rate was calculated using the formula as follows:

Growth inhibition $(\%)=100-\frac{\text { scintillation count of experimental well }}{\text { scintillation count of P.f. alone well }} \times 100$

\section{Microscopic studies}

Interaction of the phagocytic cells with parasites was observed by preparing cytocentrifuged smears of the culture. Parasites were cultured together with PMN or MNC and smears were made 48 hours later. MNC were detached from the culture plate with a rubber policeman before cytocentrifugation. The smears were air dried and stained with Giemsa for microscopic study at 1000x magnification.

Stimulation of the PMN and MNC with parasites and parasite-derived products

P. faciparum induced IL- 8 secretion by the PMN and MNC was investigated by measuring IL- 8 in the supernatant of the culture. PMN or MNC $\left(1 \times 10^{5}\right.$ cells in $100 \mu \mathrm{l}$ of medium) were cultured with viable parasitized erythrocytes
( $1 \times 10^{5}$ parasites in $5 \times 10^{7} \mathrm{RBC}$ in $100 \mu \mathrm{l}$ of medium), and the supernatant was collected by $24 \mathrm{hr}$. For positive control, PMN ( $1 \times 10^{5}$ cells in $100 \mu$ of medium) were stimulated with human recombinant TNF $\alpha(20 \mathrm{ng}$ in $100 \mu \mathrm{l}$ of medium), which was kindly provided by Dainihon Pharmaceutical Co. (Osaka, Japan).

To investigate the fraction responsible for IL-8 induction, PMN ( $1 \times 10^{5}$ cells in $100 \mu \mathrm{l}$ of medium) were stimulated respectively with intact infected erythrocytes $(1 \mathrm{x}$ $10^{5}$ parasites in $5 \times 10^{7} \mathrm{RBC}$ in $100 \mu \mathrm{l}$ of medium), $100 \mu \mathrm{l}$ of supernatant of the P.f. culture, $100 \mu \mathrm{l}$ of hemolysate of the infected erythrocytes (originally $1 \times 10^{5}$ parasites in $5 \times 10^{7}$ RBC), and partially purified $1 \times 10^{5}$ parasites obtained by hemolysing and washing out the RBC ghost. As negative control, uninfected $5 \times 10^{7} \mathrm{RBC}$ in $100 \mu \mathrm{l}$ of medium were added to the cell culture.

\section{IL-8 assay}

IL-8 in the supernatant was measured by an enzymelinked immunosorbent assay (ELISA) method as described elsewhere (Ko et al., 1992).

\section{Neutralization of IL-8 activity}

To study the role of IL-8 on parasite suppression by PMN, the cells were pretreated, 2 hours before addition of the parasites, with a mouse anti-human IL-8 monoclonal antibody WS-4 (Ko et al., 1992) at a concentration of $50 \mu \mathrm{g}$ $/ \mathrm{ml}$. For the control groups, we used monoclonal antibodies for IL-1 $\alpha$ (Kasahara et al., 1987) and an unspecific IgG. After 3 days culture, proliferation of the parasite was assessed by incorporation of $\left[{ }^{3} \mathrm{H}\right]$ hypoxanthine.

\section{RESULTS}

\section{P. f. growth inhibition}

Inhibitory effect of the MNC or PMN on P.f. proliferation depended upon the effecter to target ratio (E/T) (Fig. 1 a). $1 \times 10^{5} \mathrm{MNC}$ almost inhibited the parasite proliferation (parasite number at the start was $1 \times 10^{5} /$ well), and to get $50 \%$ growth inhibition of the parasites, we needed $0.2 \times 10^{5}$ cells, meaning the $\mathrm{E} / \mathrm{T}$ for $\mathrm{IC}_{50}$ was about 0.2 . PMN also efficiently inhibited parasite growth with the $\mathrm{E} / \mathrm{T}$ for $\mathrm{IC}_{50}$ of 0.7 (Fig. 1b). Monocytes (adherent cells) were then separated from non-adherent cells (mainly lymphocytes) and respectively cultured with the parasites. The E/T of the monocytes for $\mathrm{IC}_{50}$ was 0.9 (Fig. 2). Non-adherent cells alone showed no or minimal inhibitory effect on parasite growth. This suggests that both monocytes and lymphocytes are required to inhibit P.f. growth. 

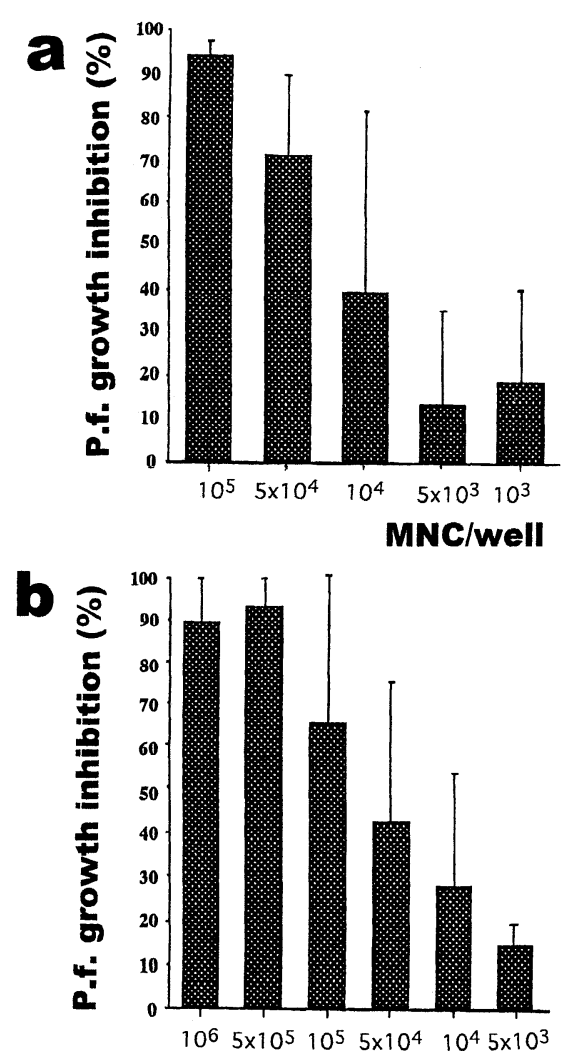

PMN/well

Figure 1 In vitro inhibitory effect of normal donors (a) MNC and (b) PMN on P.f. growth. The starting parasite number was $1 \times 10^{5} /$ well. Results are calculated as percent inhibition in relation to the $\left[{ }^{3} \mathrm{H}\right]$ hypoxanthine uptake of the P.f. alone, and presented as the mean \pm standard error from 5 isolated experiments.

\section{Morphological studies}

Morphologically, 2 days after P.f. stimulation, the monocytes greatly increased in size, and most of them contained a large number of engulfed parasites. PMN also actively phagocytosed parasites, but the number of engulfed parasites per cell was not noticeable as did the monocytes.

\section{IL-8 production of the PMN and MNC induced by P.f.}

A remarkable amount of IL-8 was detected in the supernatant of P.f. stimulated MNC. After 24 hours culture, IL -8 level in the supernatant of P.f. stimulated culture was 9 times higher than that of unstimulated one (Fig. 3). Although less prominent than the MNC, P.f. stimulated PMN also secreted a considerable amount of IL-8 (Fig. 4). The IL -8 was detectable in the supernatant after 6-9 hours of stimulation, increasing progressively with time. 24 hours later, IL-8 concentration in the supernatant of P.f. stimulated PMN was 80 times higher than that of negative control. TNF $\alpha$ at a concentration of $1 \mu \mathrm{g} / \mathrm{ml}$ also induced IL-8

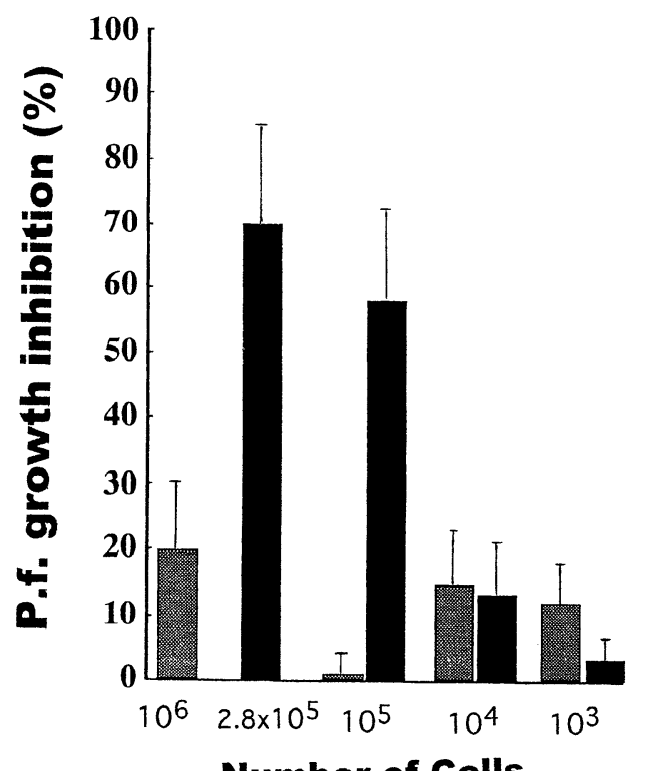

Number of Cells

Figure 2 Effect of the monocytes (black bars) and nonadherent mononuclear cells (dotted bars) for P.f. growth inhibition.

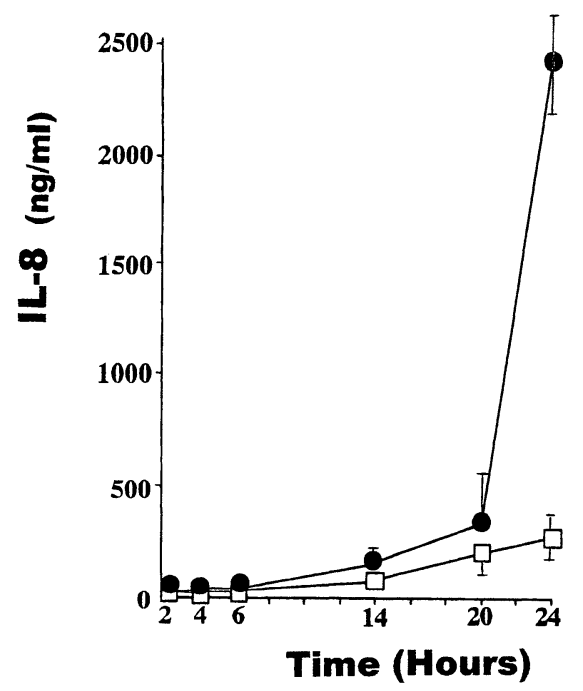

Figure 3 IL- 8 detection in the supernatant of the P.f. stimulated MNC (circles). Squares represent the value of IL-8 in the supernatant of MNC cultured with uninfected RBC.

production in PMN but no stronger than P.f. parasites did.

Experiments were also designed to determine the fraction responsible for IL-8 induction. Among the fractions tested, P.f. infected erythrocytes and supernatant of the P.f. culture were the most potent stimulants for IL- 8 production in the PMN cells. Hemolysate of the infected erythrocytes, partially purified parasites, and uninfected RBC had little or no stimulative effect on IL-8 production (Table 1). 


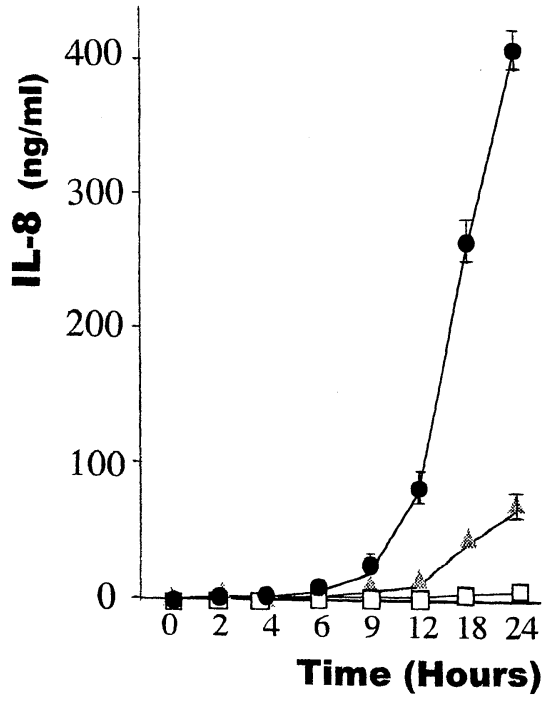

Figure 4 Time course of IL- 8 secretion in $1 \times 10^{5}$ PMN stimulated with $1 \times 105$ parasites (circles). Squares represent IL-8 detected in the PMN cultured with uninfected RBC, and triangles represent IL-8 secretion after TNF- $\alpha(100 \mathrm{ng} / \mathrm{ml})$ stimulation.

Table 1 Concentration of IL-8 (ng/ml) in the culture supernatant of PMN stimulated with infected $\mathrm{RBC}$ or P.f. products

\begin{tabular}{lcccc}
\hline & \multicolumn{4}{c}{ Period of calture } \\
& $18 \mathrm{hr}$ & $24 \mathrm{hr}$ & $32 \mathrm{hr}$ & $42 \mathrm{hr}$ \\
\hline PMN + medium & 5.1 & 6.6 & 8.3 & 12.1 \\
$\begin{array}{c}\text { PMN + } \\
\text { uninfected RBC }\end{array}$ & 5.4 & 6.0 & 5.1 & 6.7 \\
$\begin{array}{c}\text { PMN + } \\
\text { infected RBC }\end{array}$ & 140 & 610 & 1100 & 4500 \\
$\begin{array}{c}\text { PMN + supernatant } \\
\text { of P.f. culture }\end{array}$ & 140 & 370 & 1700 & 2200 \\
$\begin{array}{c}\text { PMN + hemolysate } \\
\text { of infected RBC }\end{array}$ & 16 & 68 & 130 & 250 \\
$\begin{array}{c}\text { PMN + partially } \\
\text { purified parasites }\end{array}$ & 34 & 100 & 160 & 490 \\
\hline
\end{tabular}

\section{P.f. proliferation after neutralization of the $I L-8$}

Treatment of the PMN or MNC with anti-IL-8 or antiIL-1 $\alpha$ monoclonal antibodies did not influence the inhibitory effect of these cells on parasite growth (data not shown), suggesting that IL- 8 and IL- $1 \alpha$ are not directly involved in suppression of the parasite by these cells.

\section{DISCUSSION}

Some authors have demonstrated that peripheral blood monocytes can kill malaria parasites in vivo and in vitro (Vernes, 1980; Bouharoun-Tayoun et al., 1990), but monocytes required presence of immune sera (Druilhe and Khusmith, 1987; Lunel and Druilhe, 1989) or addition of cytoki- nes (Ockenhouse et al., 1984) for activation of the cells. Peripheral blood neutrophils are also reported to be effective against P.f. in the presence of immune sera (Celada et al., 1983) or opsonins, and this activity was enhanced by TNF$\alpha$, lymphotoxin and IFN $\gamma$ (Kumaratilake et al., 1997).

We demonstrated that mononuclear cells and neutrophils from non-immune individuals efficiently inhibited P.f. growth in vitro in absence of anti-malarial antibodies or complements. Growth inhibition was dependent on the effecter/target ratio. The mechanism how the leukocytes restrain the parasite growth is not yet clear. For monocytes and macrophages, phagocytosis may be the major mechanism, as observed by morphology. The non-adherent mononuclear cells, mostly lymphocytes, did not have antiparasitic activity, but when they were incubated with monocytes, they strongly enhanced the ability of the monocytes to inhibit parasite growth. This suggests the interaction between monocytes and lymphocytes by direct contact or via cytokines. For neutrophils, the number of engulfed parasites per cell was not conspicuous. This suggests that, besides the phagocytic activity, neutrophils may produce soluble substances that may contribute to suppress parasite growth.

Cytokines have been demonstrated to be important in immunity and pathogenesis of malaria. IL-8 is a CXC type chemokine responsible for activation of a variety of cells including neutrophils (Yoshimura et al., 1987), and the receptor of IL-8 has been shown to be related to Plasmodium vivax infection (Horuk, 1994). Duffy antigen on erythrocytes has long been reported as a target molecule for vivax malaria infection (Miller et al., 1975). Interestingly, IL-8 receptor was shown to be homologous to the Duffy antigen, and the involvement of IL-8 and its receptor in infection with vivax malaria was suspected (Horuk, 1994). Some authors have detected IL-8 in the sera of P.f. infected patients (Friedland et al., 1993; Looareesuwan et al., 1999), and Wahlgren et al., (1995) have detected various cytokines, including IL-8, in the culture supernatant of P.f. stimulated peripheral blood MNC and PMN.

Our experiments demonstrated IL- 8 in the supernatant of PMN after P.f. stimulation. Since collected fraction of PMN was neutrophils by $95 \%$ and contamination with some mononuclear cells might occur, we histochemically confirmed IL-8 expression in PMN. Intracellular IL-8 was detected from 4 hours after P.f. stimulation (data not shown). Whether this IL-8 production resulted from a direct stimulation by parasites or an intermediated stimulation by a secondary cytokine has to be investigated.

In our study, we did not investigate the time required for IL-8gene expression in the P.f. stimulated PMN, but the elapsing time for IL-8 secretion may suggest presence of intermediating cytokines rather than a direct stimulation by 
the parasite. Cytokines such as TNF- $\alpha$, IL-1 and IFN $\gamma$ are demonstrated to be produced in P.f. infections (Brown et al., 1990; Wahlgren et al., 1995), and we have to consider the possibility of an autocrine stimulation by these cytokines. TNF- $\alpha$ also induced IL-8 production in the PMN (Fig.4), but PMN responded earlier and stronger to P.f. than did to TNF- $\alpha$. Thus, TNF- $\alpha$ should not be responsible for the induction of IL-8.

To elucidate the involvement of IL-8 in the immunity to falciparum malaria, we neutralized IL-8 with anti-IL-8 monoclonal antibody in the culture mixture of P.f. and PMN, resulting no abrogation of inhibitory ability to PMN. Therefore, we conclude that IL-8 has no direct influence on P.f. inhibitory activity of the PMN. The other mechanism besides IL-8 may work for inhibiting parasite growth in the culture system of malaria parasites associated with leukocytes.

\section{ACKNOWLEDGEMENTS}

We are grateful to Ms. C. Seki and Ms. M. Okada for their technical assistance.

\section{REFERENCES}

1) Bouharoun-Tayoun, H., Attanath, P., Sabchareon, A., Chongsuphajaisiddhi, T. and Druilhe, P. (1990): Antibodies that protect humans against Plasmodium falciparum blood stages do not on their own inhibit parasite growth and invasion in vitro, but act in cooperation with monocytes. J. Exp. Med., 172, 1633-1641

2) Brown, A.E., Webster, H.K., Teja-Isavadharm, P. and Keeratithakul D. (1990): Macrophage activation in falciparum malaria as measured by neopterin and interferongamma. Clin. Exp. Immunol., 82, 97-101

3) Celada, A., Cruchaud, A. and Penin, L.H. (1983): Phagocytosis of Plasmodium falciparum-parasitized erythrocytes by human polymorphonuclear leukocytes. J. Parasitol., $69,49-53$

4) Druilhe, P. and Khusmith, S. (1987): Epidemiological correlation between levels of antibodies promoting merozoite phagocytosis of Plasmodiam falciparum and malaria-immune status. Infect. Immun., 55, 888-891

5) Friedland, J.S., Ho, M., Remick, D.G., Bunnag, D., White, N.J. and Griffin, G.E. (1993): Interleukin-8and Plasmodium falciparum malaria in Thailand. Trans. R. Soc. Trop. Med. Hyg., 87, 54-55

6) Horuk, R. (1994): The interleukin-8-receptor family: from chemokines to malaria. Immunol. Today, 15, 169-174

7) Kasahara, T., Mukaida, N., Shinomiya, H., Imai, M., Matsushima, K., Wakasugi, H. and Nakano, K. (1987):
Preparation and characterization of polyclonal and monoclonal antibodies against human interleukin l $\alpha$ (IL-l $\alpha)$. J. Immunol., 138, 1804-1812

8) Ko, Y.C., Mukaida, N., Panyutich, A., Voitenok, N.N., Matsushima, K., Kawai, T. and Kasahara, T. (1992): A sensitive enzyme-linked immunosorbent assay for human interleukin-8. J. Immunol. Methods., 149, 227-235

9) Kossodo, S. and Grau, G.E. (1993): Profiles of cytokne production in relation with susceptibility to cerebral malaria. J. Immunol., 151, 4811-4820

10) Kumaratilake, L.M., Ferrante, A., Jaege, r T. and MorrisJones, S.D. (1997): The role of complement, antibody, and tumor necrosis factor alpha in the killing of Plasmodium falciparum by the monocytic cell line THP-1. Infect. Immun., 65, 5342-5345

11) Kwiatkowski, D. (1995): Malarial toxins and the regulation of parasite density. Parasitol. Today, 11, 206-212

12) Looareesuwan, S., Sjostrom, L., Krudsood, S., Wilairatana, P., Porter, R.S., Hills, F. and Warrell, D.A. (1999): Polyclonal anti-tumor necrosis factor-alpha Fab used as an ancillary treatment for severe malaria. Am. J. Tro.p Med. Hyg. 61, 26-33

13) Lunel, F. and Druilhe, P. (1989): Effector cells involved in nonspecific and antibody-dependent mechanisms directed against Plasmodium falciparum blood stages in vitro. Infect. Immun., 57, 2043-2049

14) Miller, L.H., Mason, S.J., Dvorak, J.A., McGinniss, M.H. and Rothman, I.K. (1975): Erythrocyte receptors for (Plasmodium knowlesi) malaria: Duffy blood group determinants. Science, 189, 561-563

15) Nnalue, N.A. and Friedman, M.J. (1988): Evidence for a neutrophil-mediated protective response in malaria. Parasite Inmunol., 10, 47-58

16) Ockenhouse, C.F., Schulman, S. and Shear, H.L. (1984): Induction of crisis form in the malaria parasite Plasmodium falciparum by $\gamma$-interferon-activated, monocytederived macrophages. J. Immunol., 133, 1601-1608

17) Trager, W. and Jensen, J.B. (1976): Human malaria in continuous culture. Science, 193, 673-675

18) Vernes, A. (1980): Phagocytosis of $P$. falciparum parasitised erythrocytes by peripheral monocytes. Lancet, 8207 , 1297-1298

19) Wahlgren, M., Abrams, J.S., Fernandez, V. Bejarano, M. T., Azuma, M., Torii, M., Aikawa, M. and Howard, R.J. (1995): Adhesion of Plasmodium falciparum-infected erythrocytes to human cells and secretion of cytolkines (IL-1 $\beta$, IL-1RA, IL-6, IL-8, IL-10, TGF $\beta$, TNF $\alpha$, G-CSF, GM-CSF). Scand. J. Immunol. 42, 626-636

20) Yoshimura, T., Matsushima, K., Tanaka, S., Robinson, E. A., Appella, E., Oppenheim, J.J. and Leonard, E.J. (1987): Purification of a human monocyte-derived neutrophil chemotactic factor that has peptide sequence similarity with other host defense cytokines. Proc. Natl. Acad. Sci. USA 84, 9233-9237 